\title{
Fabrication of CPW-Fed Fractal Antenna for UWB Applications with Omni-Directional Patterns
}

\author{
Tohid Sedghi, ${ }^{1}$ Mahdi Jalali, ${ }^{2}$ and Tohid Aribi ${ }^{3}$ \\ ${ }^{1}$ Department of Electrical Engineering, Urmia Branch, Islamic Azad University, Urmia 5717114653, Iran \\ ${ }^{2}$ Department of Electrical Engineering, Naghadeh Branch, Islamic Azad University, Naghadeh, Iran \\ ${ }^{3}$ Department of Electrical Engineering, Miandoab Branch, Islamic Azad University, Miandoab, Iran \\ Correspondence should be addressed to Tohid Sedghi; sedghi.tohid@gmail.com
}

Received 5 August 2013; Accepted 10 December 2013; Published 3 February 2014

Academic Editors: H. Lee and J.-K. Xiao

Copyright (C) 2014 Tohid Sedghi et al. This is an open access article distributed under the Creative Commons Attribution License, which permits unrestricted use, distribution, and reproduction in any medium, provided the original work is properly cited.

Novel and compact CPW-fed antennas are proposed comprised of a fractal patch and modified ground-plane. The groundplane is truncated at the center and includes dielectric notches at its side to enhance the antenna's impedance bandwidth. The dimensions of the notches effectively control the upper and lower band edges of the antenna. The optimized antenna operates across $2.95-12.81 \mathrm{GHz}$ for $S_{11} \leq-10 \mathrm{~dB}$. Omnidirectional radiation pattern is achieved over the full UWB frequency range. The miniaturized antenna has a total size of $14 \times 18 \times 1 \mathrm{~mm}^{3}$. The characteristics of the proposed antenna are suitable for UWB wireless communication requiring low profile antennas.

\section{Introduction}

Rapid development of wireless systems, a lot of concentration is being given for designing the UWB antennas, since they are the key elements to radiate and receive the signals [1]. There has been great progress in the design of ultrawideband antennas and devices in recent years. Several impedance alteration techniques are mentioned which vary with wide rectangular slots and circular slots with hexagonal forms [2]. One of the major challenges in the design of ultra wideband antennas is how to achieve small size antennas with low weight and desired radiation pattern characteristics and electrical properties in the band of interest [3]. The numerous numbers of slots cause more bandwidth and the optimum feed structure gives the good impedance matching [4]. Recently, some coplanar waveguide- (CPW-) fed printed monopole antennas have been reported [5-7]. This technology has offered unique advantages not achievable by conventional narrowband technology, which includes low power requirements, high speed transmission, immunity to multipath propagation, and simple hardware configuration. UWB is targeted as a cable replacement technology. Applications include wireless home networking, high-density use in business cores, wireless speakers, wireless USB, high speed WPAN, wireless sensors networks, wireless telemetry, and telemedicine.

The UWB antenna is a crucial component of such a system. The best choice for fabrication of ultrawideband antennas is on planar technology as it allows easly integration with microwave integrated circuits (MIC) and is light weight and relatively of low cost [3]. However, it is a well-known fact that conventional planar monopole antennas have relatively narrow impedance bandwidth and nonomnidirectional radiation characteristics across a significant portion of the frequency range and require a relatively large surface area. It has been shown that fractal geometries, which are based on space filling and self-similarity attributes, can be used for overcoming some of these deficiencies [4]. Also fractal based antennas can effectively couple energy to free space over their small volume $[5,6]$. Furthermore different feeding methodology can be applied on fractal antennas without degrading its performance, for example, microstrip lines [6] and coplanar waveguide (CPW) [7]. CPW transmission line feeding method is popular because of lower loss, low radiation leakage, more conveniece with shunt and series 


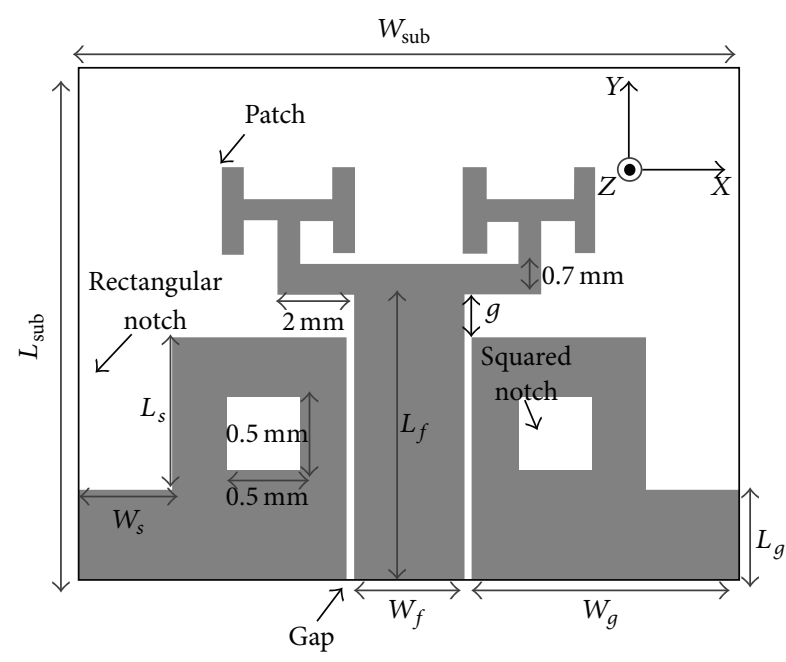

FIGURE 1: Configuration of the proposed patch antenna with CPWfed structure (Ant. II).

connection on the same side of substrate, and reliance on height of substrate for characteristic impedance [7].

In this letter, a novel and very small CPW-fed UWB antenna design is proposed consisting of a fractal patch resembling specific structure. To extend the antenna's impedance bandwidth the ground-plane is truncated at the middle with a pair of squared-shaped notches and rectangular notches are cut out from its sides. These notches affect the antenna's upper and lower band edge frequencies, thus controlling the antennas impedance bandwidth. It is also shown that by increasing the number of fractals new resonances can be generated that enhance the antenna's impedance bandwidth.

\section{Monopole Antenna Design}

The configuration and parameters of CPW-fed fractal antenna is shown in Figure 1. The antenna are etched on commercial dielectric substrate FR4 with a thickness of $1 \mathrm{~mm}$, $\tan \delta$ of 0.024 , and relative permittivity of 4.4. The substrate dimensions are $W_{\text {sub }} \times L_{\text {sub }}$. The CPW feedline has width $W_{f}$ $=3 \mathrm{~mm}$ and $\mathrm{Gap}=0.3 \mathrm{~mm}$ corresponding to a characteristic impedance of $50 \Omega$. The feedline is tapered for optimum impedance matching the antenna's fractal tree patch.

The fabricated CPW-fed antenna consists of a fractal patch with an array of fractal cells in the form similar to the branches of a tree. The antenna's rectangular groundplane is printed on the same side as the patch. To achieve a wider impedance bandwidth and hence realize UWB performance notches are cut out from its ground-plane at the sides and centers as shown in Figure 1. The process of antenna modification, illustrated in Figure 2, consists of two steps: firstly, rectangular-shaped notches are cut out from the sides of the ground-plane and secondly each part of ground-plane is truncated with squared-shaped notch at the centers and the fractal patch extended to its second iteration. This modification to the ground-plane enhances the

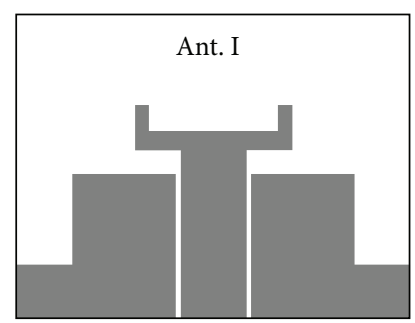

(a)

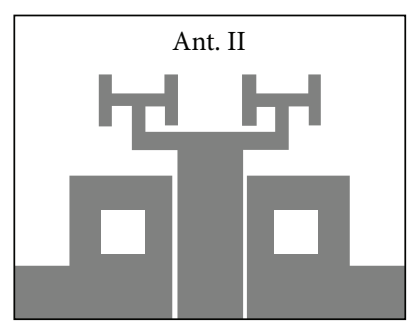

(b)
FIgURE 2: Different antenna configurations (Ant. I and Ant. II).

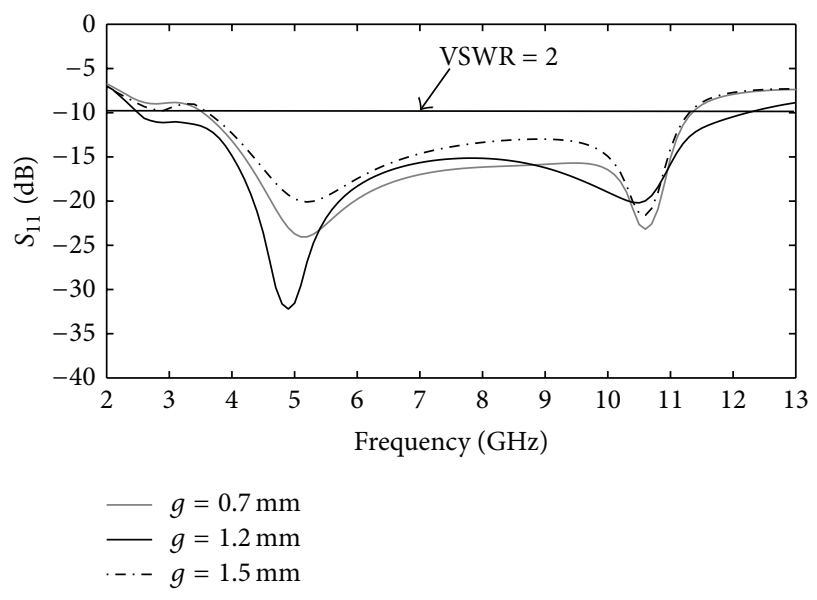

FIGURE 3: Simulated return-loss response as a function of antenna parameter $g$.

matching characteristics between the patch and the feedline which results in the antenna exhibiting UWB performance. The antenna dimensions were optimized through parametric study using Ansoft's High Frequency Structure Simulator (HFSS). Optimal parameters of the proposed antenna are as follows: $W_{\text {sub }}=18 \mathrm{~mm}, L_{\text {sub }}=14 \mathrm{~mm}, W_{f}=3 \mathrm{~mm}$, $L_{f}=7.8 \mathrm{~mm}$, Gap $=0.3 \mathrm{~mm}, W_{g}=7.2 \mathrm{~mm}, L_{g}=4.3 \mathrm{~mm}$, $L_{s}=2.3 \mathrm{~mm}$, and $W_{s}=1 \mathrm{~mm}$.

\section{Simulation and Measurement Results}

In this section, the parameters of the CPW-fed fractal antenna are discussed, and numerical and experimental results are presented. The antenna's dimensions were determined through the optimization process. The effect of individual parameters was ascertained by changing the parameter in question and keeping all other parameters fixed. The distance between the ground and the fractal patch $(g)$ has a major effect on the antenna's impedance matching attributes. Figure 3 depicts the variation of return loss $\left(S_{11}\right)$ with parameter $g$. The upper and lower values of $g$ relative to its optimized value $(g=1.2 \mathrm{~mm})$ decrease the operational bandwidth of proposed antenna. Figure 4 demonstrates the effect on $S_{11}$ for different antenna configuration in Figure 2. This figure clearly shows that a pair of squared-shaped notches on ground-plane with rectangular notches at its sides extends 


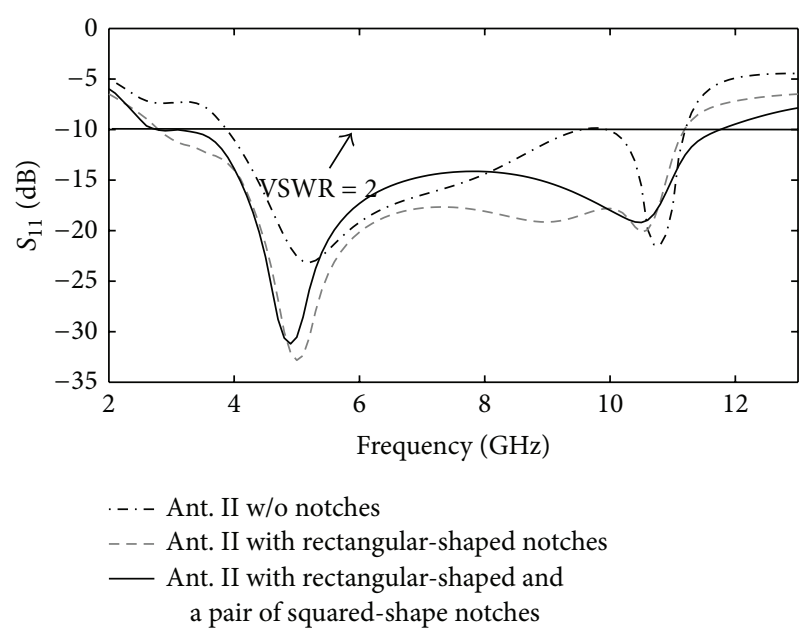

FIGURE 4: Simulated return-loss response of Ant. II with different ground configurations.

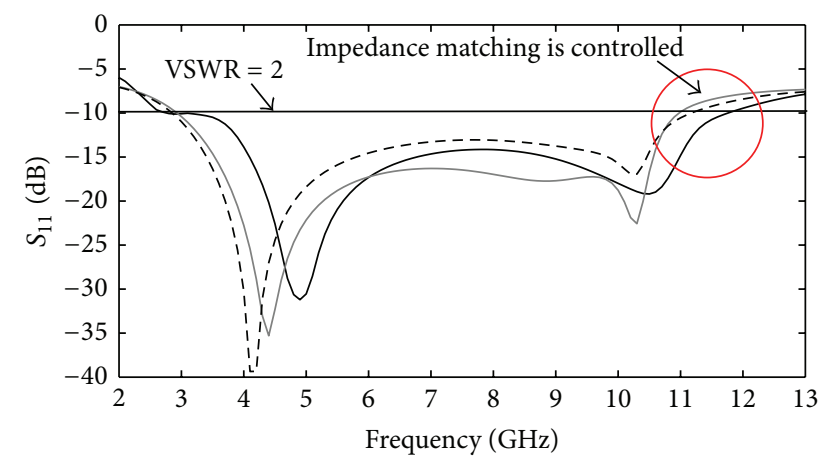

$\begin{aligned}-W_{s} & =1 \mathrm{~mm} \text { and } L_{s}=2.3 \mathrm{~mm} \\ - & W_{s}=2 \mathrm{~mm} \text { and } L_{s}=4 \mathrm{~mm} \\ \ldots-W_{s} & =3.3 \mathrm{~mm} \text { and } L_{s}=4.5 \mathrm{~mm}\end{aligned}$

FIGURE 5: Return-loss response of Ant. II as a function of parameters $W_{s}$ and $L_{s}$.

the antenna's impedance bandwidth. Figure 5 shows how the notch dimensions $\left(W_{s}, L_{s}\right)$ control the impedance matching of the antenna. It is obvious from Figure 5 that by increasing both parameters from its optimized values $\left(W_{s}=1 \mathrm{~mm}\right.$ and $L_{s}=2.3 \mathrm{~mm}$ ) the matching characteristics deteriorate and the bandwidth reduces correspondingly. The optimum values for $W_{s}$ and $L_{s}$ were obtained through parametric study.

The proposed fractal patch is composed of repeating patterns. Increasing the iteration of the fractal patch leads to the generation of strong new resonances that improves the antenna's impedance bandwidth. Antennas realized using one and two fractal iterations were fabricated on printed circuit board. The impedance bandwidth of the two antennas was measured using Agilent 8722ES S-parameter vector network analyzer $(50 \mathrm{MHz}-40 \mathrm{GHz})$.

Figure 6 shows the simulated and measured response for the two fractal antennas. It is clear that the number of fractal iterations or the number of units has great influence on return loss $\left(S_{11}\right)$. The results show that the second order iteration

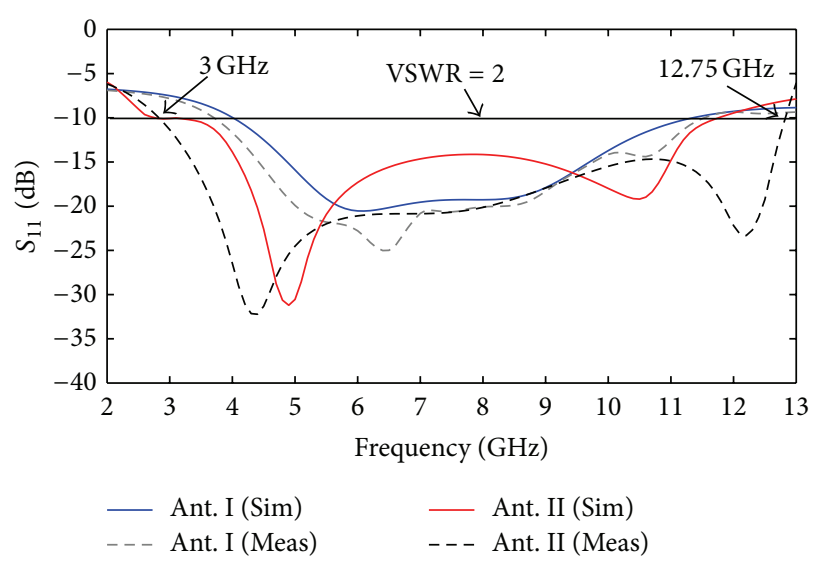

FiguRE 6: Return-loss response of Ant. I and II.

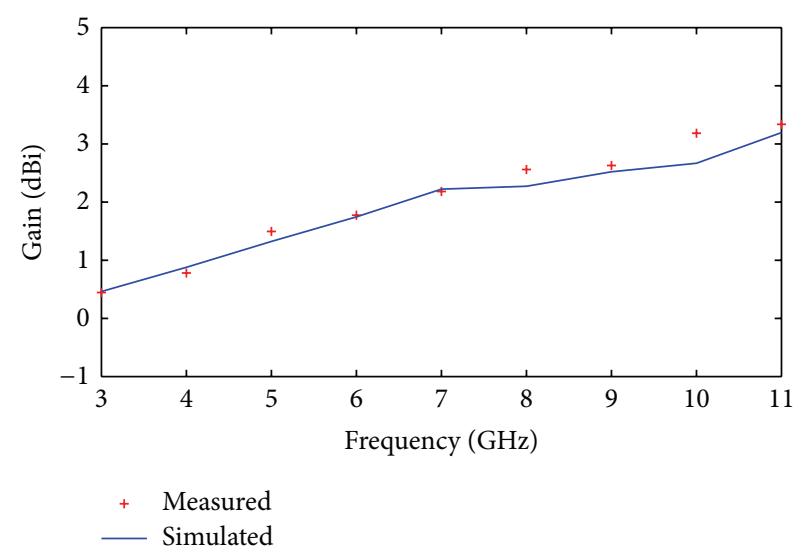

FIGURE 7: The proposed antenna's measured and simulated gain performance.

antenna completely covers the UWB range for $S_{11} \leq-10 \mathrm{~dB}$. Measured impedance bandwidth is $9.86 \mathrm{GHz}$ (from 2.95$12.81 \mathrm{GHz}$ ) with fractional bandwidth of $125 \%$. Figure 7 shows the measured antenna gain for Ant. II from 3 to $11 \mathrm{GHz}$. The measured gain of antenna appears to increase with increment in frequency as predicted by the simulated results.

The measured radiation patterns of the proposed antenna at 6 and $10 \mathrm{GHz}$ are shown in Figure 8 in the $\mathrm{H}$ - and E-planes. The H-plane radiation pattern results show that the proposed antenna is characterized by omnidirectional patterns for all in-band frequencies with cross-polarization down by more than $25 \mathrm{~dB}$. In the E-plane the radiation is bidirectional which reduces with increase in frequency. In this case the crosspolarization is $25 \mathrm{~dB}$ down.

\section{Conclusion}

A compact printed monopole antenna is presented consisting of a fractal radiating patch which is excited with a coplanar waveguide $(\mathrm{CPW})$. It is shown that with the inclusion of two pairs of notches in the ground-plane, one can extend 


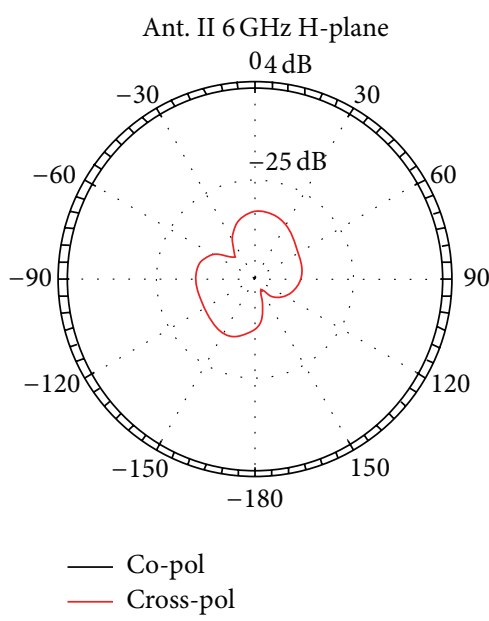

(a)

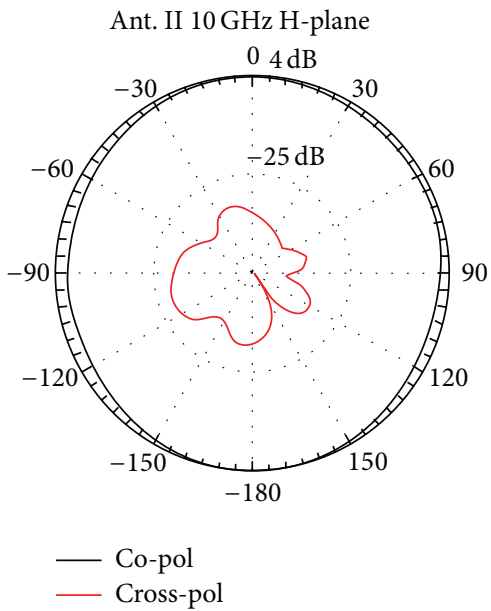

(c)

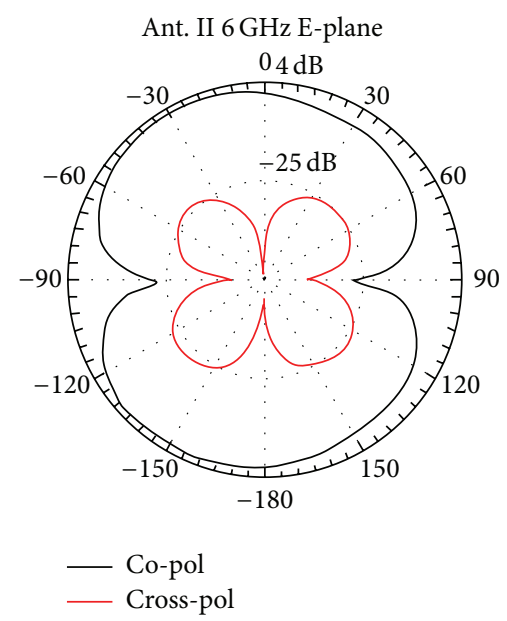

(b)

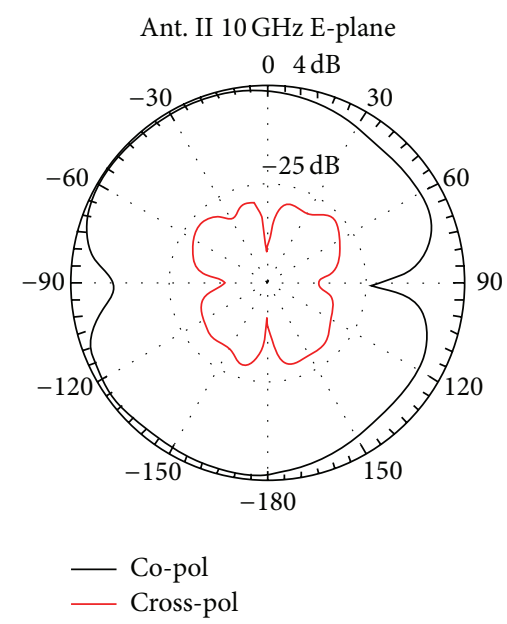

(d)

FIGURE 8: Measured radiation patterns of Ant. II at different frequencies.

the antenna's performance for ultrawideband applications. The antenna's patch is composed of a definite number of fractal cells. The antenna's parameters were investigated to fully determine the effect on its overall characteristics. Hence, the salient parameters from this analysis enabled the optimization of the antenna's performance. Experimental and simulation results demonstrate that the fractal antenna exhibits desired $S_{11}$ level and radiation pattern characteristics across the whole UWB frequency range. The measured results indicate that the antenna operates over a frequency band from 2.95 to $12.81 \mathrm{GHz}$ with fractional bandwidth of $125 \%$ for VSWR $\leq 2$. The miniaturized antenna has dimensions of just $14 \times 18 \times 1 \mathrm{~mm}^{3}$.

\section{Conflict of Interests}

The authors declare that there is no conflict of interests regarding the publication of this paper.

\section{Acknowledgments}

This paper is the result of a research project approved by the research committee at Islamic Azad University, Urmia Branch, Urmia, Iran. The authors would like to thank Islamic Azad University, Urmia Branch, for its helpful support.

\section{References}

[1] M. Koohestani and M. Golpour, "U-shaped microstrip patch antenna with novel parasitic tuning stubs for ultra wideband applications," IET Microwaves, Antennas and Propagation, vol. 4, no. 7, Article ID IMAPCH000004000007000938000001, pp. 938-946, 2010.

[2] Federal Communications Commission, "First report and order in the matter of revision of part 15 of the commission's rules regarding ultra-wideband transmission systems," Tech. Rep. ET-Docket98-153, Federal Communications Commission, Washington, DC, USA, 2002. 
[3] J.-H. Yoo and Y.-S. Lee, "Bandwidth enhancement and size reduction of microstrip-fed folded-slot antenna," Microwave and Optical Technology Letters, vol. 55, no. 10, pp. 2248-2251, 2013.

[4] H. Shirzad, B. Virdee, Ch. Ghobadi et al., "Bandwidth enhancement of compact planar microstrip antenna," ACES Journal, vol. 28, no. 5, pp. 441-445, 2013.

[5] M. Naghshvarian Jahromi, A. Falahati, and R. M. Edwards, "Bandwidth and impedance-matching enhancement of fractal monopole antennas using compact grounded coplanar waveguide," IEEE Transactions on Antennas and Propagation, vol. 59, no. 7, pp. 2480-2487, 2011.

[6] B. Ozbakis and A. Kustepeli, "The resonant behavior of the fibonacci fractal tree antennas," Microwave and Optical Technology Letters, vol. 50, no. 4, pp. 1046-1050, 2008.

[7] Ch. Deng, Y. J. Xie, and P. Li, "CPW-fed planar printed monopole antenna with impedance bandwidth enhanced," IEEE Antennas and Wireless Propagation Letters, vol. 8, pp. 1394-1397, 2009. 

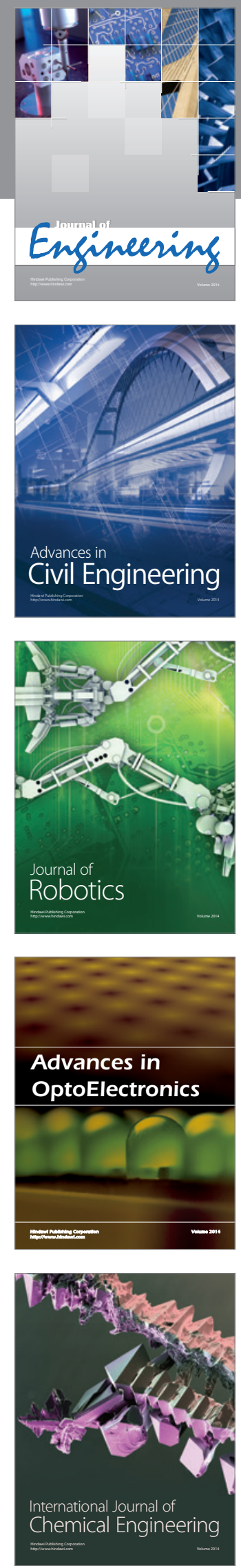

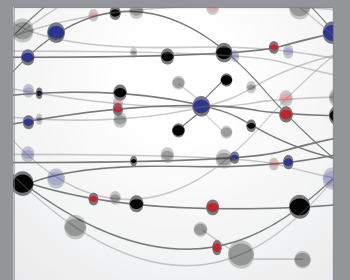

The Scientific World Journal
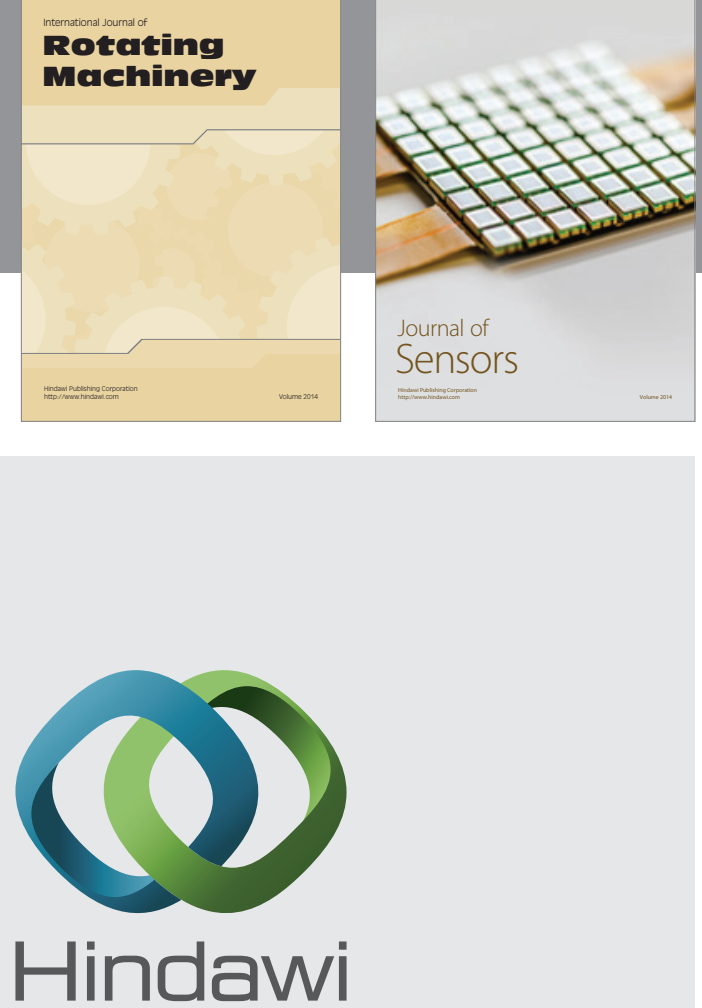

Submit your manuscripts at http://www.hindawi.com
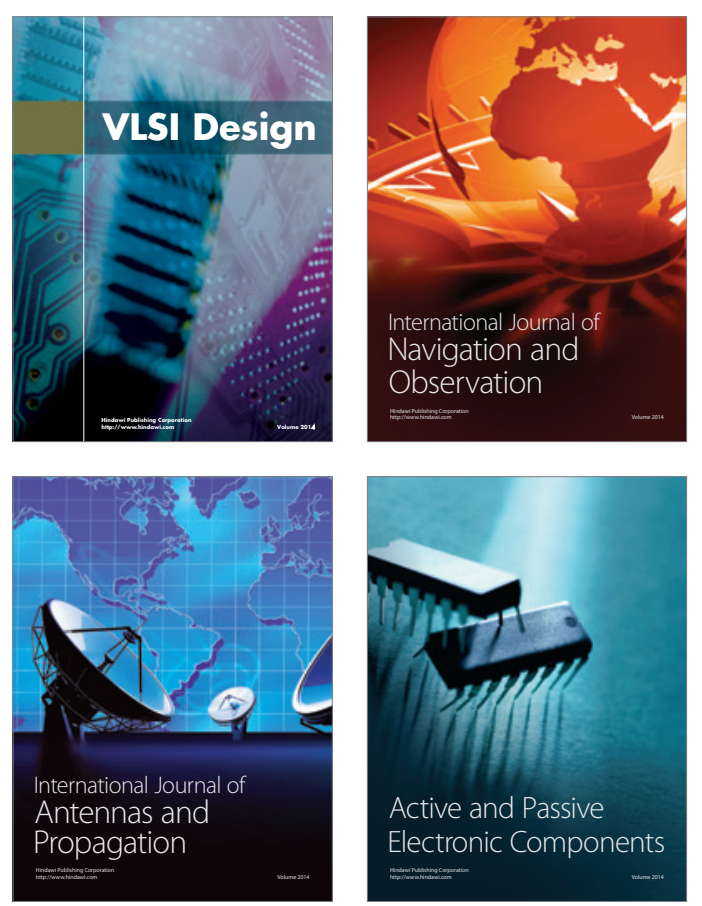
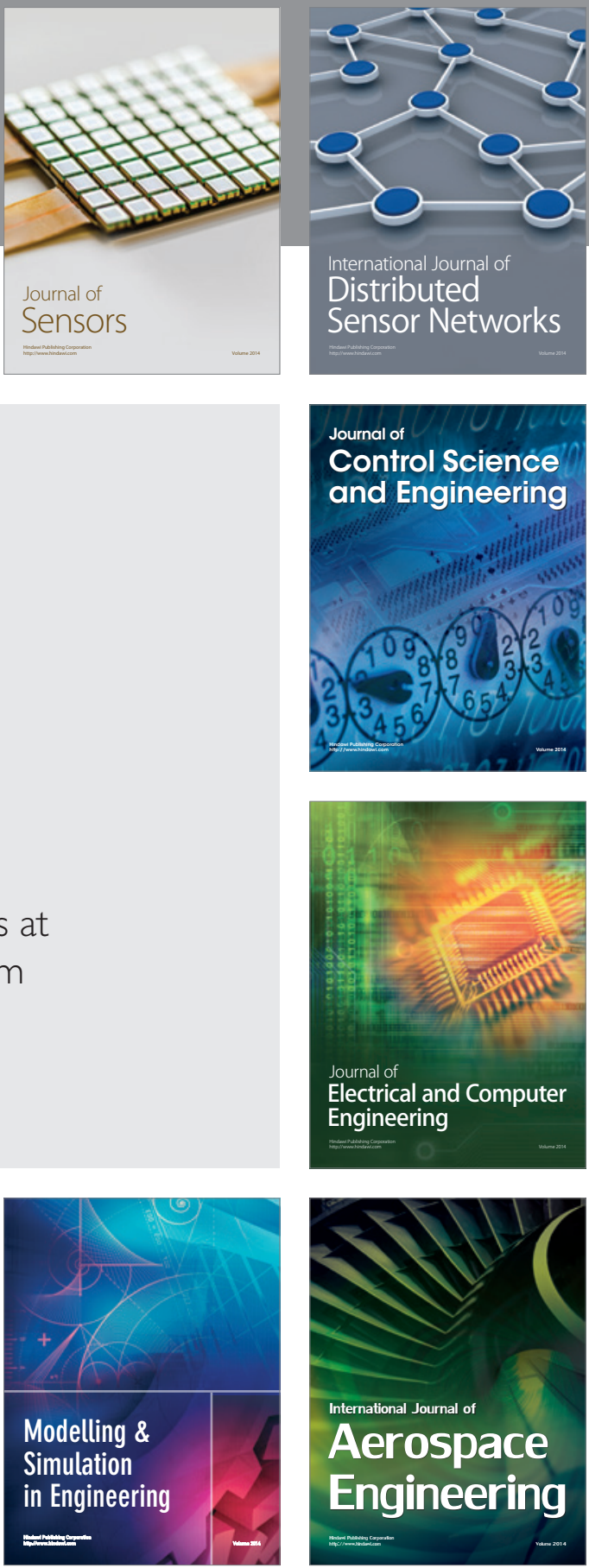

Journal of

Control Science

and Engineering
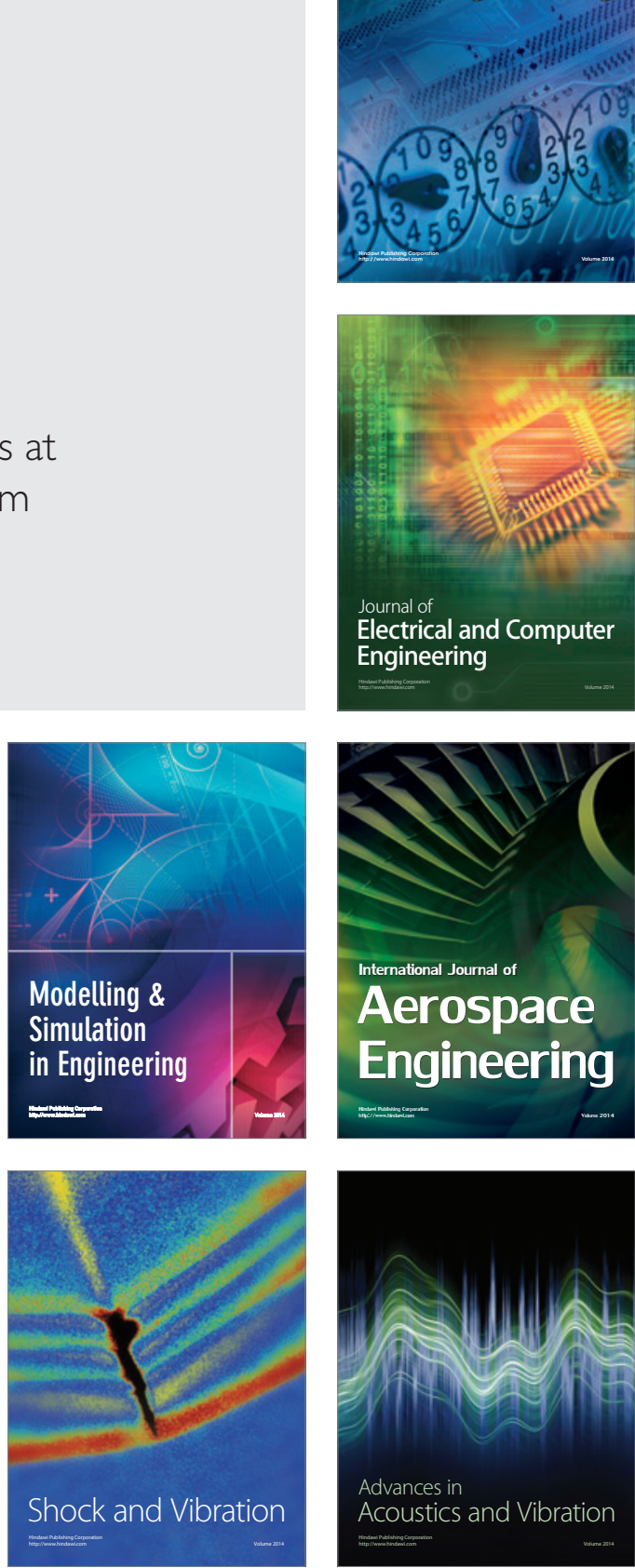